\title{
When is Open and Online Learning Relevant for Curriculum Change in Higher Education? Digital and Network Society Perspective
}

\author{
Airina Volungevičiené ${ }^{1}$, Margarita Teresevičien $\dot{~}^{1}$ and Ulf-Daniel Ehlers ${ }^{2}$ \\ ${ }^{1}$ Vytautas Magnus University, Kaunas, Lithuania \\ ${ }^{2}$ Duale Hochschule Baden-Württemberg, Karlsruhe, Germany \\ airina.volungeviciene@vdu.It \\ margarita.tereseviciene@vdu.It \\ ehlers@dhbw-Karlsruhe.de \\ DOI: 10.34190/EJEL.20.18.1.007
}

\begin{abstract}
Digital and network society learning happens in new, timeless and borderless spaces. Such society members are always connected and online, sharing and co-creating knowledge, and their learning needs serve as the biggest driving forces for higher education curriculum change. Open online learning methodology seems to be the best-suited way to implement this change, in order to meet the needs of digital and network society. This research aims to investigate why and when open online learning is relevant for digital and network society and how open online learning supports curriculum change in higher education to meet the learning needs of digital and network society members. Theoretical research findings are discussed to: a) define the characteristics of digital and networked society, b) identify emerging ways of learning of a digital and networked society, and explain why open online learning is best suited for their needs, c) discuss the gap between the new ways of learning and higher education curricula and how open online learning is relevant for its change. Empirical research is based on global experts' semi-structured interviews. The results of the research demonstrate that open online learning should serve as a solution for curriculum change in higher education to respond to digital and network society learning needs. Higher education curricula should change to ensure better flexibility, recognition of nonformal learning in formal curricula, better collaboration and exchange of people with diverse cultural and social experiences. Assessment and recognition of prior learning in the formal curricula of universities could be one of realistic scenarios for faster adaptation and introduction of more diversified learning paths. The research findings support the need to change the pedagogical approach from teacher-centred into a learner - centred, small-group orientated, multidimensional model of teaching, which raise further challenges and research dilemmas for academic community, in order to integrate important elements of change into university practices.
\end{abstract}

Keywords: digital and network society (DNS), open online learning (OOL), higher education (HE) curriculum.

\section{Introduction}

European Digital Economy and Society Index (DESI, 2018) data show that in 2017, $79 \%$ of Europeans went online regularly (at least once per week). $70 \%$ of Europeans read news online and $65 \%$ use social networks. The largest increase relates to the use of the internet for voice and video calls, where the share of the internet users went from $39 \%$ in 2016 to $46 \%$ in 2017. Students leave higher education (HE) and join diverse society groups and lifelong learners select open online learning (OOL) possibilities, including massive open online learning courses (MOOCS). The UNESCO and Commonwealth of Learning study (Patru, Balaji, 2016) reveals the potential of MOOCs to reach sustainable development goals, but Butcher and Rose - Adams (2015) argue that they are too narrow to meet learners' needs. However, universities do not change enough to meet the needs of digital and network society (DNS); to better uptake the use of digital technologies to offer $\mathrm{OOL}$ opportunities; to apply innovations in teaching and learning; and to allow better flexibility and accessibility to HE for better fulfilment of learner needs. Thus, learners search for more flexible OOL possibilities, for digital and accessible curricula, as well as for flexible forms of recognition of learning achievements (Guardia, Maina, and Sangra, 2013; Orsini-Jones, 2015).

A field of particular significance is the field of OOL, though still in early adoption. Research in OOL reveals that new innovative learning design, flexibility in time and space, and open teaching and learning models enable various society groups, of different age and with diverse possibilities, to access formal HE. However, OOL does not become a considerable part of HE available for DNS and their emerging learning needs.

We define OOL as a set of specific characteristics that are typical of open distance learning (Tait, 2000; Thorpe, 2002; Simson, 2013; Cole, Shelley, and Swartz, 2014): open and flexible learning online, ensuring accessibility to open / distance learning courses; collaboration carried out by learners in online learning activities as integral ISSN 1479-4403

CACPIL

Reference this paper: Volungevičienè, A., Teresevičienė, M., and Ehlers, U., 2020. When is Open and Online Learning Relevant for Curriculum Change in Higher Education? Digital and Network Society Perspective. The Electronic Journal of eLearning, 18(1), pp. 88-101, available online at www.ejel.org 
to both learner support and course content; developing new open knowledge and open learning practices as a result, exploiting and exploring learning groups themselves as resources for study and personal development; as well as sharing learning outcomes among learners, with the teachers and with society at large.

This research aims to investigate why OOL is relevant for DNS and how OOL supports curriculum change in HE to meet the learning needs of DNS. Research is based on literature review and empirical study. Theoretical research findings are discussed in order to:

- define the characteristics of DNS,

- identify emerging ways of learning of DNS and discuss why OOL is best suited for their needs,

- discuss the gap between the new ways of learning and HE curricula and how OOL is relevant for its change.

Empirical research is based on data collection using semi-structured interviews with thirteen experts through a wide geographical scope to support the conceptual theoretical reference of timeless and spaceless DNS. Semistructured interview questions elaborate on:

- the characteristics of DNS,

- $\quad$ emerging ways of learning of DNS nowadays,

- discussion on how universities meet the emerging needs of DNS learning ways, and

- how OOL supports transformation of HE curricula.

Qualitative data were classified using the thematic analysis model.

When it comes to curriculum development, due to its advantage of using technology for delivery over distance and time, OOL has both the potential and the need to advance to the forefront of the educational sector and can supply a solution for HE curricula to meet the emerging learning needs of DNS. This is what we want to argue in this paper.

\section{Digital and network society}

The literature review is streamlined into the following directions: a) characteristics of DNS, the changing societal context and the factors affecting the need to change curricula, b) new ways of learning in relation to $\mathrm{OOL}, \mathrm{c})$ the way HE curricula should transform, to respond better to the needs of DNS.

The term network society was coined by van Dijk (1991) and Castells (1996). Van Dijk (1991) defines the network society as a society in which a combination of social and media networks shape its prime mode of organization and most important structures at all levels (individual, organizational and societal). He compares this type of society to a mass society that is shaped by groups, organizations and communities organized in physical co-presence. Castells (2014) emphasizes that digital innovations are a fundamental factor for social changes and considers changes of organizational structures and policies to be the most important issues of DNS. We adhere to Castells' term "digital and network society" (DNS), as it highlights the important nature of digital technology and its penetration throughout society. Network and technology are the central structural characteristics of our society, playing an important role in comprising the capacity of the society to transform itself.

Besides the societal concept development, Castells' term of DNS today is an important projection of the development of new learning spaces and places. DNS is characterised by its new culture of "real virtuality" and "self-expanding network" existing in new media of transcending time and place, called "timeless time" and "space of flows" (Dijk, 1999). Globally- and physically - situated society members spend "timeless time" in the new culture of "real virtuality", capturing entirely unique learning situations, communicating unique experiences, and merging learning spaces and places into the "space of flows"; online space through multiple media.

Castells (2014), framework has been taken up by different scientists: it serves as a background to analyse the impacts of spatial transformation in the network society (Rytkönen, 2015), designing spaces for networked learning (Jones, 2015; Nordquist and Laing, 2015), and relationships between professional work and 
information communication technology in the DNS (Baker, Warburton, Hodgkin, and Pascal, 2014; Juchnevič, 2016).

The characteristics of DNS, the new culture and new dimensions of time and space, shape new characteristics of learning process; learning forms and methods, places and spaces; as well as new features of ever - changing virtual learning environments. OOL potential offers tremendous possibilities for HE institutions to improve and and move learning design to open learning spaces, to new cultures of learning and the new "space of flows". First, we need to discuss how far research in OOL defines new emerging ways of learning that best suit DNS members.

\section{Emerging learning ways}

Researchers suggest that digital technologies will radically transform what people learn, how they learn, and where they learn (McLoughlin and Lee, 2010; Redecker, 2011), yet there exists some disagreement on the speed and scope of this change. Hutchison, Tin, and Cao (2008) indicate that the existing dominant systems of education were built by and for baby-boomers in the industrial world; whereas the current generation of users operates in DNS with mobile devices in hand, and are creative, result-oriented, self-focused, achievementoriented and comfortable in an image-rich interactive environment. These target groups enter educational systems with different expectations, which, together with societal contexts, need to be reflected in curriculum development.

One characteristic of emerging learning ways among DNS members is that formal, non-formal and informal education are gradually merging and clear boundaries between these sectors are blurring (Cameron and Harrison, 2012). Learners can explore more than what they get from a traditional classroom. People have started to take part in online learning networks based on their personal or professional interests. Digitalization has opened entirely new possibilities for education and learning. The rise of $\mathrm{OOL}$, realised through such forms as open educational resources, MOOCs, collaborative activities and others, show a great potential of providing university level education free from traditional conditions, such as cost and academic background (Chuang and Ho, 2016; Graham et al., 2018; Katy, 2014) offering other attractive forms of OOL and bringing new challenges. Knowledge and information are widely accessible online, creating opportunities for learning in different ways.

Online learning provides the possibility of accessing information in extended and fragmented formats to develop in-depth perspective, as well as a wide and complex approach to the phenomenon (Knerr, 2013). Therefore, digital competence is fundamental for participation in education, social, cultural and political life (Mavrou, 2017) and hence, learning in DNS and digitally enhanced educational experiences play a vital role for social integration, educational success, employment opportunities, and overall quality of life (Krumsvik, 2009; Stone, O’Shea, May, Delahunty, and Partington, 2016).

Many characteristics of new learning ways preferred by DNS match very well the characteristics of OOL. Research in $\mathrm{OOL}$ argues that $\mathrm{OOL}$ improves collaboration, successfully innovates pedagogies for effective social interaction online, and leads to improved student achievements (Laurillard, 2009). OOL supports active learning, participation and co-creation of knowledge and sharing of experiences. Good practices are described in terms of involving DNS members to create and distribute quality content of a variety of formats through various media channels, to implement peer evaluation and peer learning, collaboration and integration of shared knowledge bases of subjects involved (Arruabarrena, Sanchez, Blanco, Vadillo and Usandizaga, 2019).

One of the most emphasized characteristics of the way DNS learns is how people are connected online and participate in the network, how they constantly share, as well as interact with their peers. Interaction is the one of the key characteristics of $\mathrm{OOL}$, tightly linked with the purpose it us used for. Hernandez-Lara, PereraLluna and Serradell-Lopez (2019) claim that communication, interaction and collaboration methods used in $\mathrm{OOL}$ improve learning results. Extensive research publications describe how OOL may open $\mathrm{HE}$ and change and improve curricula through integrating social networks and promoting collaborative learning (Fernandez-Ferrer, Cano, 2016). OOL by nature integrates technology enhanced learning solutions through digital learning environments, digital media and resources, where DNS members find their new "virtual reality" and the new culture of learning. 


\section{How should learning and teaching change?}

In order to adapt and reflect on the opportunities and risks which digital technology poses to educational and learning processes, HE institutions have to take the development challenges on board. While many steps have been taken already to evaluate new possibilities for learning and teaching, curriculum development is still one step behind. Today it is clear that digitalization is not a technological revolution in $\mathrm{HE}$ if it is not an innovation in learning design and organization of educational experiences.

The curriculum is expected to respond to the developments and changed contexts of a DNS. These are the features and the elements of the new pedagogical approach that would respond to the needs of DNS and are supported by OOL methodologies:

- Different learners' characteristics, experiences, cultures, and learning abilities (Hood and Littlejohn, 2016). DNS is an example of the diversity of learners who represent lifelong learners networking in virtual space, connecting from their physical places, local economies, cultures and communities, sharing their individual and personal, as well as community experiences online within a dedicated network for formal and non-formal learning.

- Tate and Klein-Collins (2012) refer to increasing numbers of "non-traditional" learners or adults, sharing some of the traits such as having dependents, being a single parent, working full-time, being independent from parents or attending school part-time. One of the features of OOL is accessibility to those social groups who were prevented from participation due to constraints of time and socio economic conditions. OOL has long been praised for providing access to all disadvantaged groups.

- The teacher-centred approach changes into a "personalized, small-group orientated, multidimensional model of teaching" (Sun, 2011). Active learning methods used in OOL, interactive learning through the use of digital learning resources, peer learning and peer reviewing, collaborative online activities and co-creation of knowledge illustrate both, the new attractive learning methods, and learner - centred learning design.

- $\mathrm{OOL}$ has the potential to attract more students with wide-ranging interests, ensuring more appealing learning opportunities (Meier, 2015). The new forms of OOL, including MOOCs, demonstrated how attractive flexible and self-directed learning. Student lifelong learning model should not be restricted to the traditional students, but ways should be opened for all DNS members to merge formal and non-formal OOL opportunities and receive recognition of their learning results.

- Hoadley (2012) suggests that for a better understanding of undergoing changes, teachers should find answers to the questions: what learning is; how learning should be designed; how knowledge can be organized; how learning is enabled in practice and how it can be assessed. These changes lead to advantages, such as smaller classroom size, better student-teacher interaction, ability to reuse open courses, lower costs and flexibility (Byrd and Mixon, 2012).

- Kovanovič et al. (2018) approach curriculum transformation at its extreme, through the learners' transition from knowledge-consumer to knowledge-provider. As already discussed, involvement of students in knowledge co-creation and sharing proves to have a very positive impact on student motivation and learning results improvement.

- The development of assessment and recognition procedures which are stressed by political decisions (Bologna Open Recognition Declaration, 2016) and research (Muñoz, Redecker, Vuorikari, and Punie, 2013; Witthaus et al., 2016). The importance of assessment and recognition at universities and the necessity of being on top of these developments is an increasingly important factor for competitiveness in a highly diverse and globalised education market.

Literature and good practice review argue that new learning industries formulate a multidimensional concept that allows transformation of educational practices and the nature of HE through new characteristics of OOL.

DNS wants to learn through global participation, community engagement, application of the flipped classroom, when students access content outside the class and spend class time discussing, analysing, and applying new information (St Clair, 2015). Therefore, it is important for HE institutions to appropriately consider how new practices and learning outcomes are contextualised. Discussions and clarification of options and models for recognition of OOL are still in progress (Muñoz et al., 2013). 
The research shows that HE digitalisation is making fast progress. However, little evidence is available how well HE curricula today are aligned to meet the new challenges, and how that can be done. Therefore, an empirical qualitative study has been carried out to find how HE curriculum can respond to DNS needs, and what innovations are needed to empower learners through OOL HE curriculum.

\section{Methodology of the empirical research}

The research has been designed to address the extent of alignment of HE curricula towards the changing contexts of the emerging learning needs. For the purpose, a qualitative research strategy was chosen to study the complex phenomenon by helping to understand human experience and to reveal the subjective meaning and interpretation of instances of individual experiences without isolating them from the context (Creswell, 2014; Flick, 2009).

\subsection{Data Collection and Analysis}

Semi-structured interviews were used for data collection. Five open-ended questions were defined to clarify:

- $\quad$ characteristics of DNS;

- emerging ways of learning;

- changing university role to meet learning needs of DNS;

- the description of the transformation of the OOL curriculum; and, finally,

- the impact of transformation of the OOL curriculum upon the organization of the learning process.

The qualitative data were analysed by using the six-phased thematic analysis model documented by Braun and Clarke (2006) (see Figure 1).

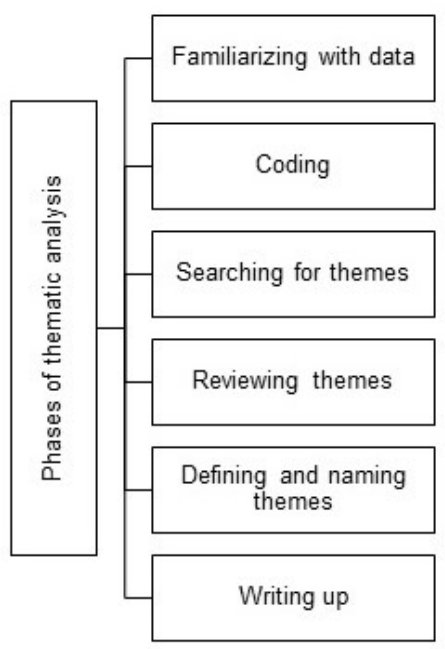

Figure 1: The phases of thematic analysis (based on Braun and Clarke, 2006).

Thematic analysis is seen as one of the most flexible methods for qualitative data analysis as its model is not linear and does not require to be applied step-by-step. Rather, it is recursive, when the researcher can move from one phase to another without completing a prior phase (Clarke and Braun, 2013; Nowell, Norris, White, and Moules, 2017).

\subsection{Research participants}

Purposive sampling was applied for the selection of research participants, based on their relevance to the research question and ability to share expert knowledge on the need for the change of $\mathrm{OOL}$ in $\mathrm{HE}$, considering emerging learning needs of DNS.

The following criteria were applied for the selection of research participants:

- experts involved in the activities of one of the biggest European or global professional associations in the area of OOL;

- experience of at least 10 years of working in the field of OOL, either implementing OOL in HE or working with $\mathrm{OOL}$ solutions for $\mathrm{HE}$; 
- $\quad$ experts representing different countries worldwide and working with DNS members (either creating $\mathrm{OOL}$ solutions or being involved in innovating non-formal and formal $\mathrm{HE}$ ).

The data were collected by face-to-face and online interviews. All interviews were recorded, the majority of them in the English language, some in Lithuanian and then translated into English. There were no issues arising from the language versions nor interview mode (online or face-to-face). There were 13 interviews conducted with experts aged 28 to 60, working on a policy level, in international associations, $\mathrm{HE}$ and private companies, representing 8 countries. All experts were either creating $\mathrm{OOL}$ solutions for $\mathrm{HE}$ institutions or were involved in one or another way in non-formal and formal HE innovations that help to meet the learning needs of DNS. The experts were invited for the interview during the international events and volunteered for the interviews. The size of the whole sample of experts meeting the selection criteria is not known, but during the international conferences and seminars the selection criteria were announced to session participants and the ones who volunteered were invited for the interview. The characteristics of interviewees are presented in Table 1:

Table 1: Characteristics of research participants

\begin{tabular}{|c|c|c|c|c|c|}
\hline $\begin{array}{l}\text { Participant } \\
\text { code }\end{array}$ & Gender & $\begin{array}{c}\text { Experience of } \\
\text { working in OOL } \\
\text { (years) }\end{array}$ & Work position & Type of institution & Country \\
\hline 11 & $F$ & 11 & Researcher & University & Lithuania \\
\hline 12 & $\mathrm{M}$ & 10 & Researcher & University & Italy \\
\hline 13 & $\mathrm{~F}$ & 15 & $\begin{array}{l}\text { Policy maker, } \\
\text { administrative staff }\end{array}$ & University & Croatia \\
\hline 14 & $\mathrm{~F}$ & 10 & $\begin{array}{l}\text { Practitioner, administrative } \\
\text { staff }\end{array}$ & University & Croatia \\
\hline 15 & M & 12 & $\begin{array}{l}\text { Researcher, practitioner, } \\
\text { administrative staff }\end{array}$ & University & Hungary \\
\hline 16 & $\mathrm{~F}$ & 10 & Researcher & $\begin{array}{l}\text { International } \\
\text { foundation }\end{array}$ & Spain \\
\hline 17 & M & 11 & $\begin{array}{l}\text { Researcher, practitioner, } \\
\text { administrative staff }\end{array}$ & University & Germany \\
\hline 18 & M & 18 & $\begin{array}{l}\text { Researcher, practitioner, } \\
\text { administrative staff }\end{array}$ & University & Spain \\
\hline 19 & $\mathrm{M}$ & 12 & Policy maker, researcher & Private company & Malta \\
\hline 110 & $\mathrm{~F}$ & 10 & $\begin{array}{l}\text { Practitioner, teacher, } \\
\text { administrative staff }\end{array}$ & University & Lithuania \\
\hline 111 & $\mathrm{~F}$ & 10 & $\begin{array}{l}\text { Researcher, teacher, } \\
\text { administrative staff }\end{array}$ & University & Lithuania \\
\hline 112 & $\mathrm{~F}$ & 11 & Practitioner & Private company & Hungary \\
\hline 113 & M & 10 & $\begin{array}{l}\text { Researcher, company } \\
\text { owner }\end{array}$ & Private company & USA \\
\hline
\end{tabular}

The thirteen experts represent a wide geographical scope, in order to purposefully support the conceptual theoretical reference of timeless and spaceless DNS on the global reach.

\subsection{Research ethics}

This study is guided by the principle of interviewees' volunteering consent to participate in the research (Flick, 2009). The analysis of the data has also been guided by the principle of impartiality, in order to see the data as they are, and aiming to disclose the transformation of open and online learning curricula in higher education without any preconditions.

\subsection{Research limitations}

There are some limitations that should be considered regarding this research. Firstly, the qualitative research strategy reflects subjective experiences of research participants, thus the research results cannot be generalized. Moreover, interviewees who were chosen based on purposive sampling may not reveal all the potential approaches towards the research question. Therefore, the thematic map may represent only a part of themes and sub-themes which are important for the research question. Finally, the fact that most of the interviewees and researchers themselves were non-native English speakers is also seen as an important limitation of the study. 


\section{Research results and analysis}

The process of thematic analysis allowed the distinguishing of key elements that were evident in the data. Based on this, themes were defined as seen to be essential and summarizing research participants' approaches. These themes have been named as "Constantly connected and learning online", "Universities as knowledge-based hubs" and "Empowering learners through opening online higher education curriculum" (see Fig. 2).

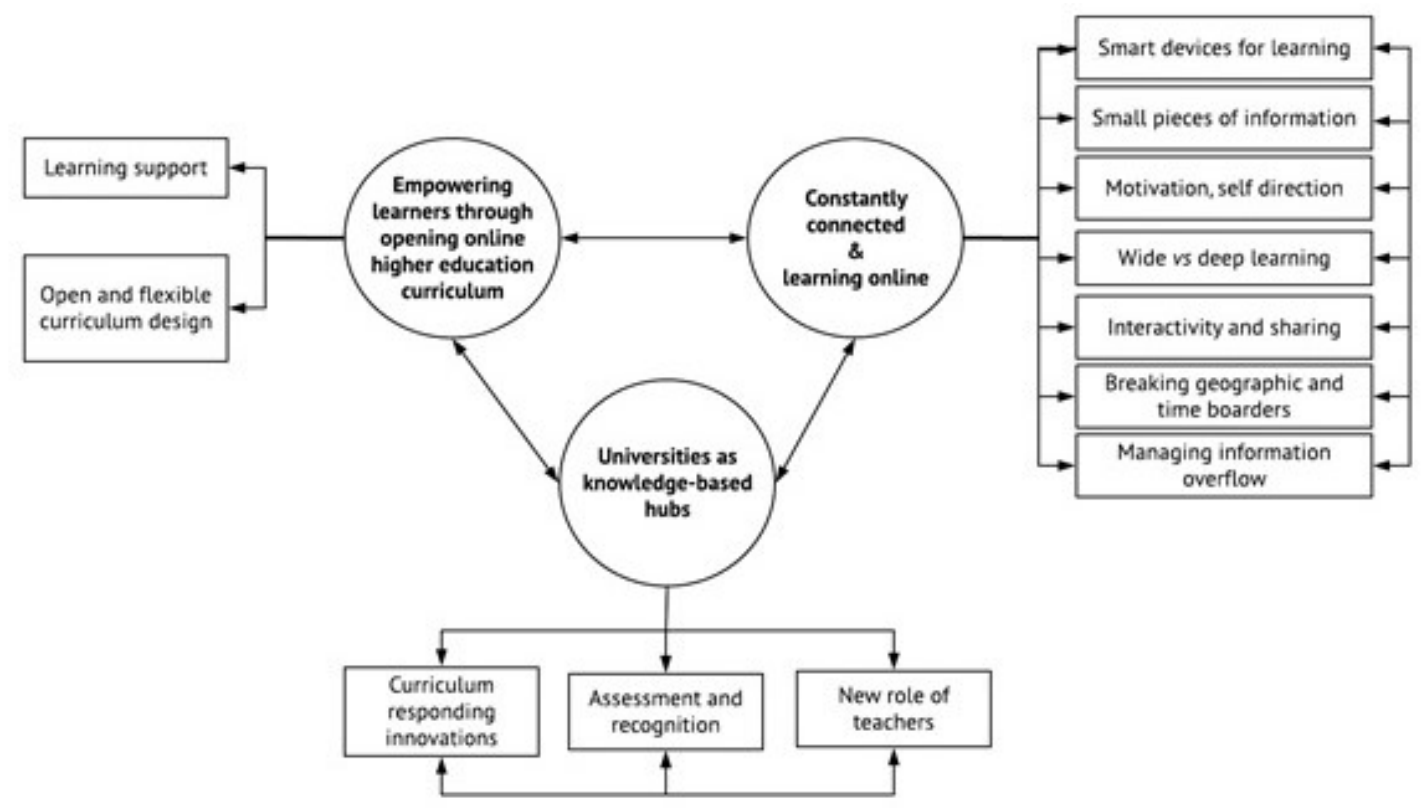

Figure 2: Thematic map on changing curriculum in HE.

The research data demonstrate that all the elements of curriculum change in HE are interrelated.

\subsection{Constantly connected and learning online}

DNS refers to persons who are able to use technologies in their daily life and who are connected by technological means: smartphones, tablets or computers; people who browse the internet every day and read and/or comment on the news by using their phones or other technologies. To belong to DNS one needs to communicate or at least relate oneself to a certain digital community by being a member of a social network, by subscribing or reading and participating in online discussions on certain news pages or blogs, or by joining closed online group discussions, or at least following them.

DNS is quite a new phenomenon developed through the enhancement of reality by technological tools. We establish and develop networks, and these networks "have their own lives" and their own impact upon the society:

... it is smarter, it is more about being network connected (I13).

Our concern today is to find proper and good quality information. DNS members may and should be able to decide on the sources and the channels where information and the news come from, and they usually decide what version of the news or information they prefer:

... because we have too much information, and we have to be able to choose from this information" (I12).

The speedy dissemination of knowledge and information is one of the characteristics of DNS. There are no national or regional boarders in the network society, people connect with each other globally, and global network members can get access to the same knowledge immediately. Time differences are no longer important. Information flow and channels allow us to reflect on issues we would not have thought of before: 
... it's about interconnection of people, the exchange of knowledge, it's not limited anymore to physical locations like an institution, it's open. Because of that you don't have any boundaries anymore, so the digital and network society has no boundaries anymore, that's a major element of it. (I7)

DNS means no or less physical interaction, with virtual interaction dominant. Lots of connections, interactivity, innovative ways of sharing knowledge and skills in a group:

I think it's all about sharing ideas, the really fundamental need of humans to interact and to share what they have achieved and to learn something new from others (14).

New technological devices such as mobile phones, tablet computers, and social networks are becoming central for learning. Boundaries between formal, non-formal and informal learning are gradually weakening, everyone can choose and use a learning way that suits them. Moreover, learning happens everywhere in the open online environment:

Every time we connect to the online community, we learn. We sometimes don't feel that we learn, but every new experience, every piece of knowledge that gives us input for new ideas and reflections, and changing any behaviour or thinking is a way of learning; and nowadays it is very easy to learn by participating in an online community, as people tend to share interesting, valuable pieces of information that influence our thinking and knowledge. (I10)

This data proves that $\mathrm{OOL}$ environments are suitable solutions for new ways of learning. HE curricula should be changed to integrate seamlessly informal and non-formal learning into formal OOL HE.

Since we are constantly online, whenever a disagreement during a dispute occurs, despite our physical whereabouts, it is very common for us to pick up a mobile device and to check information immediately. At the time we share, search for, or validate information, we naturally include our experience and communication into our learning.

These statements reconfirm the need for innovating pedagogies in formal education, allowing students to cocreate knowledge and to share quality learning resources, as well as to receive immediate validation of information and interactivity.

Searching and sharing knowledge and information in smaller portions, making decisions and solutions much quicker, spending less time for the analysis of what is written or spoken become emerging ways of learning. We live in a faster society and world, and we, as individuals, have to minimize the acquisition of information, which is fragmented. In order to absorb all new things or new elements we need to take smaller portions of everything:

I see shorter and shorter modules and lessons in this digital world, which was not the case 10 years ago, the trainer society was quite reluctant to minimize the knowledge, so that is a kind of transformation, easy access, quick access for small chunks, small bits of learning. (15)

Digital forms and new media formats have raised challenges for information scalability and presentation online. OOL reflects these challenges, thus sometimes it is "accused" of wide vs deep learning through reading, listening or watching. However, this topic needs much further analysis and is interrelated with cognitive characteristics of human beings, as well as with new pedagogy of online learning. We would rather not be corrupted by the new media forms by transferring their principles into chosen pedagogical approach but had better search for didactical solutions maintaining the principles of a pedagogical scenario and learning objectives, not generalising with the characteristics of the new media and information publishing formats:

This is only a different way of approaching knowledge. We are living in a society that allows you to go deep in one dimension or to stay on the top and have a wide perspective of all the feelings of the subjects and so on. I strongly believe that at the moment the knowledge of the learner stays maybe too much on the wide perspective and does not go into the deep perspective. (I2)

There is a tendency among DNS members to focus on limited topics and brief news. However, this may show characteristics of a more complex phenomenon: DNS members may prefer scrolling through wide horizontal 
levels of information, instead of going into narrow, but deep, vertical levels, and they can demonstrate the ability to see multidisciplinary connections that others have never seen before:

Today even myself, I'm not going so deep, I have lots of information and it's important that I understand it and then just collect the pieces and build my knowledge upon them. So, I don't go very deep into each subject, but I'm just building based on more information than before. I think today the youngsters are also doing it this way. (I3)

Online learners are diverse in their nature, needs, and preferences. There is a tendency to characterise them as self-directed learners, as they manage to diagnose their own learning needs, to identify appropriate resources for learning, and to choose appropriate learning strategies. However, others need some structured help. Self-directed learners are highly motivated, and they themselves usually select and validate all the information available. This fact has direct and huge impact towards the entire education system, and it changes the level of knowledge exchange dramatically, because:

... now young people, living in the village, not having access and the possibility of going to university, will now have the chance to gain knowledge and to build on the knowledge and be successful in life, so that's a very important element. (I7)

The trends and characteristics of OOL include self-directed and personally motivated learners, responsible for their learning. This proves that education providers should revise their approach to curriculum development and delivery, as future learning will all be online and open.

\subsection{Universities as knowledge-based hubs}

In DNS, the role of universities changes, as they need to fit into a new context in the education field, to respond to technological innovations, to find out how to balance between tradition and openness. Universities are still an effective place that brings together the creation of knowledge and teaching, creating a link between research and teaching. "And so that means universities as knowledge transfer hubs, universities as team leaders and professional networks, universities as research hubs" (19).

On the one hand, universities strive to prepare people for a highly technologically advanced society, a technologically advanced workplace; therefore, they are important actors in DNS, as well as promoters of lifelong learning. On the other hand, universities are in great competition with other types of knowledge providers; besides, some individuals still choose a university because of the diploma and certificates rather than gaining knowledge. Moreover, a popular belief is that one can get the necessary knowledge from the internet, from private providers, from open online courses:

... if this person has gained knowledge through the internet, through online courses, through MOOCs provided by private institutions, companies don't care anymore if they have no official certificates from the university" (17).

Indeed, companies have less focus on certificates, but stronger focus on skills. If universities do not respond to the change, the market and society members will change faster than the former. More and more people will start exploring alternative routes, which are much more diverse than the HE landscape. More flexible learning possibilities are much more attractive to learners:

Definitely the idea of open learning is something that is revolutionary, more or less like the first radio transmission because it changes completely and instantly the idea of learning. The idea of openness is something that you can reuse .... we need to reprogram the university like they did it from the Bologna process, it's exactly the same. (12)

OOL pedagogical approach is related with a change in a teachers' role. Learning is more likely to happen when a learner is engaged and active. The learning process needs to be organized in a way which makes it learnercentred:

... it's a question of the quality of the teaching that is actually being offered, how it is actually being offered and what the students can actually make the most of. And also, in terms of how you package 
that information, are we talking about the degree or mass qualifications... or is it some kind of lifelong learning. (18)

Assessment and recognition of prior learning used in formal education must adapt to the emergence of much more diversified learning paths. The problem of the open learning is the recognition of learning results in the formal curricula, which you cannot do without paying the tribute to formal bureaucracy:

What I strongly believe is that now we are learners in everything that we are doing online, but at the same time we don't have recognition of what we are learning during this time spent online, on Facebook, on YouTube, and so on. (12)

The new systems of digital credentialisation and certification are in the process of development, but they need valid solutions in place. Other challenges addressed by $\mathrm{OOL}$ include recognition of learning by companies and the private sector:

We need something more like the Bologna process once again, to have something that could be recognized everywhere at organizational level and also the virtual mobility so structurally related, because as soon as you have a common framework, you will have the possibility of obtaining your knowledge and your formal recognition everywhere, independently of where you are and where you want to study. (12)

\subsection{Empowering learners through opening online higher education curriculum}

Flexibility and openness is crucial for the OOL HE curriculum, as learning with no geographical or time boarders is an increasingly preferred form of learning, particularly for students who are employed, study part time, live in remote places or have fewer possibilities for accessing information and materials while traveling.

Obviously, we need to emphasise pedagogical and technological support for students. The pedagogical support may be provided by the teacher, while the necessity for technological support depends a lot on the students' digital competence and information provided. There is a need to present students with suggestions on how to learn online. The possibility of asking for help should always be open. When changing curriculum to OOL, universities will become 24-hour institutions, offering 24 - hour digital studies around different parts of the globe:

... and that's how we get into this whole lifelong learning experience and that's why I think it is so important, the way we can package up learning into smaller, more agile components that can actually be purchased by our students. (18)

The needs of lifelong learners will be met by universities who will arrange their curriculum in smaller units and shorter programs, developing learning programs together with industry and DNS members. We need to think about how to structure the curriculum and the interactive learning process. Short exercises, short videos, immediate feedback on quizzes and tests, technology that supports learning - all these elements lead to rethinking about how universities should organize teaching and learning process, and how the curriculum is structured in terms of competences and learning outcomes. If individuals are taking a course, a constant feedback during their studies should be provided, so they can make judgement of how well they are doing or how much there is to be done, and whether they are satisfied with their own progress:

What is obvious that learners... don't want to sit for an hour and watch a lecture, then what you can do is take a curriculum and slice it into the learning achievements, learning outcomes, whatever you want to call them, and make it focused; it might be a lecture or more of an animation, but short... Then you have to really think about your teaching, then you have to think about how you organize your teaching, and how your curriculum is organized. (I13)

The structure of the curriculum can be very different: based on linear learning, what we usually do in our universities, or individualized learning, self-paced, or an entire study program modularly built by a student, and if an institution would be offering these as modules then the learners could have their own personal curriculum: 
... so [we have to] begin to rethink the typical course environment and how we differentiate between courses and how they are structured; often very linear, or doing Google searches, completely unstructured and non-linear, ... I think it leads to new ways to think about individualized learning, selfpaced learning, and it can be really interesting. (17)

To sum it up, the thematic map on changing OOL curriculum in HE (see Fig. 2) highlights the features of DNS, the role of universities, which act as research and knowledge-based hubs, and changes in learning responding to the needs of DNS.

\section{In conclusion}

The results of the empirical part of this research reveal that technological innovations are used in the teaching process at universities, and the role of universities is in progress towards the change of their curricula to meet emerging ways of learning DNS, but there is much work ahead and a lot needs to be done to take important elements of change into practices. There exist examples of more flexible non-formal learning solutions for DNS, in particular with MOOC offers (Chuang and Ho, 2016), where millions of students are already studying online. More and more people start exploring alternative routes and have a much more diverse HE landscape to enjoy.

The challenge that universities face is based on the learning needs of DNS, such as constant online connection, a broad spectrum of interactivity, overwhelming amounts of information and innovative ways of sharing knowledge in groups with no time or geographical boundaries. Network and technology have become the central structural characteristics (Castells, 2014) of DNS, while digital innovations are a fundamental factor for social changes. Change of $\mathrm{HE}$ curriculum implies changes to organizational structures and policies of universities.

Individuals apply digital tools for learning in "timeless time" controlled by "space of flows" (Castells, 1996). They are equipped with internet connection and tend to learn in new places and with new tools. The pressure is on significantly faster acquisition of knowledge, which should be introduced in smaller portions to meet the challenge of living in a much faster society and the world. Members of DNS are more focused on wide rather than deep information acquisition and learning. These findings support the results of previous researches stating that with the appearance of different digital devices there appear new sources of information. The new approach offers new perspectives and opportunities for knowledge creation, sharing and innovations.

The research findings support the need to change the pedagogical approach from teacher-centred into a learner - centred, small-group orientated, multi-dimensional model of teaching where the structure can be very different, either based on linear learning or, on the contrary, completely unstructured, individualized, selfpaced, modular, or even personal curriculum based on learning outcomes or competences.

The change of HE curriculum into $\mathrm{OOL}$ is related to the changes of a teacher's role. The need for interactivity takes the central role in HE didactical change, to make it easier for individuals to share knowledge, experiences and perceptions of their interaction with the instructor, content, and other learners (Stone et al., 2016).

The empirical evidence of the research proves the need for universities to respond to existing challenges and to introduce technological and pedagogical innovations, design flexible and dynamic modes of learning, and to design a flexible curriculum divided into smaller units of credits, preferably in cooperation with industry and DNS members.

The research data confirm the need for OOL recognition. Assessment and recognition of prior learning in the formal curricula of universities should demonstrate an adaptation of much more diversified learning paths.

\section{Acknowledgement}

The research has been implemented within the framework of the research project "Open and Online Learning for Digitalised and Networked Society" (project No. 09.3.3-LMT-K-712-01-0189) funded by the European Social Fund according to the activity "Improvement of researchers" qualification by implementing world-class R\&D projects' of Measure No. 09.3.3-LMT-K-712. 


\section{References}

Arruabarrena, R., Sanchez, A., Blanco J. M., Vadillo, J., Usandizaga, I. 2019. Integration of good practices of active methodologies with the reuse of student-generated content. International Journal of Educational Technology in Higher Education, pp. 1-20. DOI: https://doi.org/10.1186/s41239-019-0140-7. Available at https://educationaltechnologyjournal.springeropen.com/articles/10.1186/s41239-019-0140-7 [Accessed 21 May 2019].

Baker, S., Warburton, J., Hodgkin, S., and Pascal, J. 2014. Reimagining the relationship between social work and information communication technology in the network society. Australian Social Work, 67(4), pp. 467-478. DOI: https://doi.org/10.1080/0312407X.2014.928336

Bologna Open Recognition Declaration. 2016. Available at https://medium.com/openrecognition/bologna-openrecognition-declaration-4d977ab91c3 [Accessed 17 January 2019].

Braun, V., and Clarke, V. 2006. Using thematic analysis in psychology. Qualitative Research in Psychology, 3(2), pp. 77-101. DOI: http://dx.doi.org/10.1191/1478088706qp063oa

Byrd, J., and Mixon, P. 2012. Revenues and E-learning: do universities need an online presence? Journal of Higher Education Policy and Management, 34(6), pp. 601-609. DOI: https://doi.org/10.1080/1360080X.2012.727704

Butcher, J. and Rose-Adams, J. 2015. Part - time learners in open and distance learning: revisiting the critical importance of choice, flexibility and employability. Open Learning: the Journal of Open, Distance and e-Learning, 30(2), pp. 127-137. DOI: https://doi.org/10.1080/02680513.2015.1055719 Available at https://www.tandfonline.com/doi/full/10.1080/02680513.2015.1055719 [Accessed 21 May 2019].

Cameron, R., and Harrison, J. L. 2012. The interrelatedness of formal, non-formal and informal learning: evidence from labour market program participants. Australian Journal of Adult Learning, 52(2), pp. 277-309. Available at: https://files.eric.ed.gov/fulltext/EJ1000165.pdf [Accessed 18 January 2019].

Castells, M. 2014. The impact of the internet on society: A global perspective. MIT Technology Review. Available at: https://www.technologyreview.com/s/530566/the-impact-of-the-internet-on-society-a-global-perspective/ [Accessed 18 January 2019].

Castells, M. 1996. The information age: economy, society and culture. The rise of the network society (Vol. 1). Oxford: Blackwell.

Chuang, I., and Ho, A. 2016. HarvardX and MITx: Four years of open online courses. http://dx.doi.org/10.2139/ssrn.2889436

Cole, M.T., Shelley, D/J., and Swartz, L.B., 2014. Online instruction, e-learning, and student satisfaction: A three year study. The International Review of Research in Open and Distributed Learning, 15(6). DOI: 10.19173/irrodl.v15i6.1748. Available at http://www.irrodl.org/index.php/irrodl/article/view/1748 [Accessed 10 May 2019].

Clarke, V., and Braun, V. 2013. Teaching thematic analysis: overcoming challenges and developing strategies for effective learning. The Psychologist, 26(2), pp .120-123.a Available at: http://eprints.uwe.ac.uk/21155 [Accessed 18 January 2019].

Creswell, J. 2014. Research design: qualitative, quantitative, and mixed methods approach ( $4^{\text {th }}$ ed.). Thousand Oaks, CA: SAGE Publications Inc.

Digital Economy and Society Index Report 2018. Use of Internet Services. European Commission. Available at <https://ec.europa.eu/digital-single-market/en/use-internet> [Accessed 21 May 2019].

Fernandez-Ferrer, M., Canon, E. 2016. The influence of the internet for pedagogical innovation: using twitter to promote online collaborative learning. International Journal of Educational Technology in Higher Education, DOI: https://doi.org/10.1186/s41239-016-0021-2. Available at https://educationaltechnologyjournal.springeropen.com/articles/10.1186/s41239-016-0021-2. [Accessed 10 May 2019].

Flick, U. 2009. An introduction to qualitative research (4th ed.). Thousand Oaks, CA: SAGE Publications Ltd.

Graham, Ch., Vaughan, N., Dziuban, Ch. Teodoro, D., V. 2018. Blended Learning in Higher Education: research findings. International Journal of Educational Technology in Higher Education. Available at https://www.springeropen.com/collections/blhe. [Accessed 18 January 2019].

Guardia, L., Maina, M., and Sangra, A. 2013. MOOC design principles. A pedagogical approach from the learner's perspective. eLearning Papers, 33, pp. 1-5. Available at: https://www.researchgate.net/publication/239608003 MOOC Design Principles A Pedagogical Approach from $t$ he Learner's Perspective [Accessed 20 May 2019]

Hernandez-Lara, A., Perera-Lluna, A., Serradell-Lopez, A. 2019. Applying learning analytics to students' interaction in business simulation games. The usefulness of learning analytics to know what students really learn. Computers in Human Behavior, 92, pp. 600-612. DOI: https://doi.org/10.1016/j.chb.2018.03.001. Available at https://www.sciencedirect.com/science/article/pii/S0747563218301067. [Accessed 10 May 2019].

Hoadley, U. 2012. Curriculum: Organising knowledge for the classroom (3rd ed.). Cape Town: OUP/Saide.

Hood, N., and Littlejohn, A. 2016. MOOC quality: The need for new measure. Journal of Learning for Development, 3(3), pp. 28-43. Available at: http://www.jl4d.org/index.php/ejl4d/article/view/165/157 [Accessed 18 January 2019].

Hutchison, M., Tin, T., and Cao, Y. 2008. "In-your-pocket" and "On-the-fly": meeting the needs of today's new generation of online learners with mobile learning technology. In T. Anderson (Ed.) The theory and practice of online learning, pp. 201-220. Available at: http://www.aupress.ca/books/120146/ebook/99Z Anderson 2008-

Theory and Practice of Online Learning.pdf [Accessed 18 January 2019]. 
Jones, C. 2015. Networked learning. An educational paradigm for the age of digital networks. Dordrecht: Springer. Juchnevič, L. 2016. Šiuolaikiniai bibliotekos konceptai tinklaveikos visuomenejje: kontekstas ir požiūriai // Contemporary concepts of the library in a network society: Context and approaches. Informacijos mokslai // Information sciences, 75, pp. 95-114. DOI: https://doi.org/10.15388/Im.2016.75.10153

Katy, J. 2014. Initial trends in enrolment and completion of massive open online courses. International Review of Research in Open and Distance Learning, 15(1), pp. 133-160. DOI: http://dx.doi.org/10.19173/irrodl.v15i1.1651

Knerr, C. 2013. No, Google is not making us stupid. [blog comment]. 11 June, 2013. Available at: https://www.avaya.com/blogs/archives/2013/06/stupid-google.html [Accessed 18 January 2019].

Kovanovic, V., Joksimovic, S., Poquet, O., Hennis, Th., Cukic, I., de Vries, P., Hatala, M., Dawson, Sh., Siemens, G., and Gasevic, D. 2018. Exploring communities of inquiry in Massive Open Online Courses. Computers \& Education, 119, pp. 44-58. DOI: https://doi.org/10.1016/i.compedu.2017.11.010

Krumsvik, R. R. 2009. Situated learning in the network society and the digitised school. European journal of teacher education, 32(2), pp. 167-185. DOI: https://doi.org/10.1080/02619760802457224

Laurillard, D. 2009. Technology enhanced learning as a tool for pedagogical innovation. Journal of Philosophy of Education, 42(3-4), pp. 521-533. DOI: https://doi.org/10.1111/j.1467-9752.2008.00658.x. Available at https://onlinelibrary.wiley.com/doi/abs/10.1111/j.1467-9752.2008.00658.x [Accessed 21 May 2019]

Lee, A.R., Son, S.-M., and Kim, K.K. 2016. Information and communication technology overload and social networking service fatigue: A stress perspective. Computers in Human Behavior, 55 (Part A), pp. 51-61. DOI: https://doi.org/10.1016/j.chb.2015.08.011

Mavrou, K., Meletiou-Mavrotheris, M., Kärki, A., Sallinen, M., and Hoogerwerf, E. 2017. Opportunities and challenges related to ICT and ICT-AT use by people with disabilities: An explorative study into factors that impact on the digital divide. Technology \& Disability, 29(1/2), pp. 63-75. DOI: https://doi:10.3233/TAD-170174

McLoughlin, C., and Lee, M. J. W. 2010. Personalised and self-regulated learning in the Web 2.0 era: international exemplars of innovative pedagogy using social software. Australasian Journal of Educational Technology, 26(1), pp. 28-43. DOI: https://doi.org/10.14742/ajet.1100

Meier, E. 2015. Beyond a digital status quo: Ree-conceptualizing online learning opportunities. Bank Street Occasional Paper Series, 34, pp. 5-19. Available at: https://educate.bankstreet.edu/occasional-paperseries/vol2015/iss34/2?utm source=educate.bankstreet.edu\%2Foccasional-paperseries\%2Fvol2015\%2Fiss34\%2F2\&utm medium=PDF\&utm campaign=PDFCoverPages [Accessed 18 January 2019].

Muñoz, J.C., Redecker, CH., Vuorikari, R., and Punie, Y. 2013. Open education 2030: Planning the future of adult learning in Europe. The Journal of Open, Distance and e-Learning, 28(3), pp. 171-186. DOI: https://doi.org/10.1080/02680513.2013.871199

Nordquist, J., and Laing, A. 2015. Designing spaces for the networked learning landscape. Medical Teacher, 37(4), pp. 337343. DOI: https://doi.org/10.3109/0142159X.2014.1001349

Nowell, L. S., Norris, J. M., White, D. E., and Moules, N. J., 2017. Thematic analysis. Striving to meet the trustworthiness criteria. International Journal of Qualitative Methods. 16, pp. 1-13. DOI: https://doi.org/10.1177\%2F1609406917733847

Orsini-Jones, M. 2015. Innovative pedagogies series: integrating a MOOC into the MA in English language teaching at Coventry University: innovation in blended learning practice. Higher Education Academy. Available at: https://www.heacademy.ac.uk/system/files/marina_orsini_jones_final_1.pdf [Accessed 18 January 2019].

Patru, M., Balaji, V., 2016. Making sense of MOOCS: a guide for policy makers in developing countries. Commonwealth of Learning, UNESCO. Available at https://unesdoc.unesco.org/ark:/48223/pf0000245122 [Assessed 20 May 2019]

Redecker, C., Ala-Mutka, K., Leis, M., Leendertse, M., Punie, Y., Gijsbers, G., Kirschner, P., Stoyanov, S., and Hoogveld, B. 2011. The future of learning: preparing for change. Available at: http://ftp.jrc.es/EURdoc/JRC66836.pdf [Accessed 18 January 2019

Rytkönen, E. 2015. University campuses in spatial transformation: a business model typology of case Aalto Universitya Facilities, 33(13/14), pp. 794-818. DOI: https://doi.org/10.1108/F-04-2014-0042

Simpson, O., 2013. Supporting students in online open and distance learning. New York and London: Routledge.

St Clair, R., Winer, L., Finkelstein, A., Fuentes-Steeves, A., and Wald, S. 2015. Big hat and no cattle? The implications of MOOCs for the adult learning landscape. Canadian Journal for the Study of Adult Education, 27(3), pp. 65-82.

Available at:

https://pdfs.semanticscholar.org/Ofce/3681220b7e4f55f47f96b6049776ecceb8cf.pdf? ga=2.77050581.1310532116. 1537994895-1902850465.1537994895 [Accessed 18 January 2019].

Stone, C., O'Shea, S., May, J., Delahunty, J., and Partington, Z. 2016. Opportunity through online learning: experiences of first-in-family students' online open-entry higher education. Australian Journal of Adult Learning, 56(2), pp. 146-169. Available at: https://files.eric.ed.gov/fulltext/EJ1107574.pdf [Accessed 18 January 2019].

Sun, S. Y. H. 2011. Online language teaching: the pedagogical challenges. Knowledge Management \& E-learning: an International Journal, 3(3), pp. 428-447. Available at: https://doaj.org/article/65d65666610f494b96f8cbc2c06f4b66 [Accessed 18 January 2019].

Tait, A. 2000. Planning student support for Open and Distance Learning. Open Learning: the Journal of Open, Distance and e-Learning, 15(3), pp. 287-299. DOI: https://doi.org/10.1080/713688410. Available at https://www.tandfonline.com/doi/abs/10.1080/713688410 [Accessed 21 May 2019] 
Tate, P., and Klein-Collins, R. 2012. IT innovations and the non-traditional learner. In D. G. Oblinger (Ed.), Game changers: education and information technologies, pp. 67-80. Educause. Available at: https://www.educause.edu/ /media/files/library/2012/5/pub72035-pdf.pdf?la=en [Accessed 18 January 2019].

Thorpe, M. 2002. Rethinking tlearner support: he challenge of collaborative online learning. Open Learning: the Journal of Open, Distance and e-Learning, 17(2); pp. 105-119, DOI: https://doi.org/10.1080/02680510220146887a. Available at https://www.tandfonline.com/doi/abs/10.1080/02680510220146887a [Accessed 20 May 2019]

Van Dijk, J. A. G. M. 1991. De netwerkmaatschappij: Sociale aspecten van nieuwe media. Houten: Bohn Staflen van Loghum.

Van Dijk, K. A. G. M., 1999. The on-dimensional network society of Manuel Castells. New Media \& Society, 1(1), pp. 127138. DOI: $10.1177 / 1461444899001001015$. Available at https://journals.sagepub.com/doi/10.1177/1461444899001001015 [Accessed 21 May 2019]

Witthaus, G., Inamorato dos Santos, A., Childs, M., Tannhäuser, A., Conole, G., Nkuyubwatsi, B., and Punie, Y. 2016. Validation of non-formal MOOCS-based learning: An analysis of assessment and recognition practices in Europe (OpenCred). Publications Office of the European Union. DOI: http://dx.doi.org/10.2791/809371 